\title{
Caracterização produtiva e de regularização ambiental da carcinicultura na região do vale do Paraíba
}

\begin{abstract}
A carcinicultura no Brasil se desenvolve a mais de 30 anos com períodos de ascensão e queda, contudo é um segmento consolidado na produção de proteína animal, gerando milhares de empregos e movimentando a econômica em locais com poucas oportunidades de trabalho. A produção, no Brasil, se concentra na região Nordeste, onde é produzido aproximadamente $95 \%$ do camarão cultivado no país. Essa região possui condições ambientais e climáticas favoráveis à criação de camarões. Considerando que a carcinicultura é uma atividade exercida principalmente por pequenos produtores rurais, os quais atuam com baixo capital financeiro, sem todas as regularizações ambientais necessárias e com baixo monitoramento ambiental na produção, esse trabalho tem o objetivo de realizar a caracterização da carcinicultura na região do Vale do Paraíba, e assim, proporcionar um melhor entendimento sobre a carcinicultura e sua sustentabilidade na região. Para isso, foram realizadas entrevistas "in loco" em 20 empreendimentos produtores de camarão na região. Os resultados demonstram que $40 \%$ das propriedades têm até 1 hectare de área produtiva e $55 \%$ delas possuem de 1 a 2 pessoas trabalhando na produção. Poucos empreendimentos da região estão regularizados do ponto de vista ambiental e apenas $50 \%$ deles fazem algum tipo de monitoramento nesta área. Concluir-se que a carcinicultura no Vale do Paraíba é uma atividade exercida, sobretudo, por micro e pequenos produtores. É necessário que os empreendimentos da carcinicultura busquem a regularização de suas atividades, evitando-se a paralização do negócio e prejuízos ambientais e financeiros. Além disso, é indispensável que os produtores aumentem suas capacidades de realizar um adequado monitoramento ambiental, principalmente, nos parâmetros de qualidade de água e efluentes gerados na produção do camarão. Os resultados desse estudo são de fundamental importância para subsidiar futuros estudos científicos e tecnológicos em prol da cadeia produtiva da carcinicultura.
\end{abstract}

\section{Productive characterization and environmental regularization of carciniculture in Paraíba valley region}

\begin{abstract}
Shrimp farming in Brazil has been growing over more than 30 years, with increasing and decreasing periods, however, it is a consolidated segment in animal protein production, generating thousands of jobs and moving the economy in places with few job opportunities. Production is concentrated in the Northeast, where approximately $95 \%$ of shrimp farmed in the country is produced. This region has favorable environmental and climatic conditions for shrimp farming. Considering that shrimp farming is an activity mainly carried out by small farmers, who operate with low financial capital, without all the necessary environmental regulations and with low environmental monitoring in the production, this work aims to characterize shrimp farming in Paraiba Valley region, and thus provide a better understanding of shrimp farming and its sustainability in the region. For that, interviews were carried "in loco" in 20 plants producing shrimp in the region. The results show that $40 \%$ of the properties have up to 1 hectare of productive area and $55 \%$ of them have 1 to 2 people working in the production. Few ventures in the region are environmentally regulated and only $50 \%$ of them do some kind of environmental monitoring. It should be concluded that shrimp farming in Paraiba Valley is an activity mainly carried out by micro and small producers. It is necessary that these shrimp farming plants seek to regularize, avoiding business stoppage and environmental and financial damages, in addition, it is indispensable that the producers increase their capacities to carry out an adequate environmental monitoring, mainly, concerning water quality and effluents generated in shrimp production. The results of this study are fundamental to support future scientific and technological studies related to carciniculture production.
\end{abstract}

Keywords: Diagnosis; Litopenaeus Vannamei; Aquaculture; Small Producer.

Topic: Sistemas de Gestão Ambiental

Reviewed anonymously in the process of blind peer.

Thiago Dias Trombeta

Universidade Catolica del Norte, Chile

http://lattes.cnpq.br/2803207476967537

thiago trombeta@yahoo.com.br

Rui Dias Trombeta

Universidade Federal de Viçosa, Brasil

http://lattes.cnpq.br/7072400530480598

rui@ecofishconsultoria.com
Received: 18/07/2017

Approved: 19/10/2017
Referencing this:

TROMBETA, T. D.; TROMBETA, R. D.. Caracterização produtiva e de regularização ambiental da carcinicultura na região do vale do Paraíba. Revista Ibero-Americana de Ciências Ambientais, v.8, n.4, p.245-254, 2017. DOI: http://doi.org/10.6008/SPC2179-6858.2017.004.0020 


\section{INTRODUÇÃO}

A carcinicultura no Brasil se iniciou nos anos 80, com um crescimento expressivo a partir de 1996 por meio da disseminação da espécie Litopenaeus vannamei, principal camarão produzido atualmente no mundo (ROCHA, 2003; FAO, 2016). Em 2001, já com o domínio do ciclo reprodutivo e a autossuficiência na produção de náuplios e pós-larvas do Litopenaeus vannamei, o país tornou-se líder em produtividade de camarão em um curto espaço de tempo (BORGHETTI et al., 2003; ROCHA, 2006).

Entretanto, a partir de 2004, evidenciou-se uma queda brusca na produção devido a enfermidades e problemas de ordem econômica, como a ação de dumping imposta pelos Estados Unidos e a forte desvalorização do dólar americano (DIEGUES, 2006; NATORI et al., 2011). A partir desses episódios, a produção começou a se reestruturar, adotaram-se novas práticas de produção e direcionou-se o produto ao mercado interno brasileiro (ROCHA, 2011), havendo a cada ano taxas positivas de crescimento.

De acordo com o último registro oficial, o Brasil produziu 68 mil toneladas de camarão no ano de 2014 (FAO, 2016). O país se destaca pelo fato da produtividade da carcinicultura ser considera uma das maiores do mundo, com média de $3.505 \mathrm{~kg} / \mathrm{ha} / \mathrm{ano}$, estando, acima da média mundial que, é de $931 \mathrm{~kg} / \mathrm{ha} / \mathrm{ano}$ (ABCC, 2013).

A região Nordeste do Brasil é responsável por aproximadamente $95 \%$ do camarão marinho produzido no país, predominando na atividade micros, pequenos e médios produtores, com destaque para os Estados do Ceará e Rio Grande do Norte, que concentram o maior número de empreendimentos (TAHIM et al., 2014; IBGE, 2015). O potencial da região nordeste é evidenciado pela extensa faixa litorânea e às condições favoráveis de clima, hidrologia e topografia para o cultivo de camarão marinho (CASTRO et al., 2004).

A carcinicultura no Estado da Paraíba é caracterizada pela produção em águas salobras em empreendimentos instalados ao longo do Vale do Rio Paraíba. Segundo a ABCC (2011), o polo costeiro é composto por 41 fazendas, localizadas principalmente no litoral Norte, já o polo do interior conta com cerca de 50 fazendas produtoras de camarão.

A criação de camarões é uma atividade capaz de gerar transformações regionais, por meio de percepções dos produtores e atores da cadeia produtiva quanto ao uso sustentável e ordenado dos recursos hídricos, sobretudo, na promoção do desenvolvimento econômico alavancando melhoria na qualidade de vida das pessoas envolvidas. Joventino et al. (2008), destaca o potencial da carcinicultura no desenvolvimento socioeconômico do Nordeste, sobretudo, em regiões onde as oportunidades de negócios são limitadas ou escassas. Diante desse contexto, esse trabalho tem o objetivo de realizar a caracterização produtiva da carcinicultura na região do Vale do Paraíba, e assim, proporcionar um melhor entendimento sobre a carcinicultura e sua sustentabilidade na região.

\section{METODOLOGIA}

Foram visitadas 20 propriedades na região do Vale do Paraíba, selecionadas aleatoriamente, por meio de um cadastro da Associação dos Carcinicultores da Paraíba (ACPB). A coleta das informações foi 
realizada in loco por meio da aplicação de questionários diretamente com o empresário e funcionários do empreendimento/propriedade selecionada.

Os aspectos abordados no questionário para compor o estudo foram: comunicação e organização das propriedades, porte dos empreendimentos, utilização de energia elétrica, mão de obra empregada, características dos viveiros de produção, densidades de estocagem, taxa de sobrevivência, uso de aeradores e alimentadores, ciclos de produção, monitoramento ambiental, regularização ambiental e tratamento de efluentes. As propriedades entrevistadas se localizavam nos seguintes municípios: Itabaiana/PB, Itatuba/PB, Mogeiro/PB, Pilar/PB, Salgado de São Felix/PB e São Miguel de Taipú/PB.

\section{RESULTADOS E DISCUSSÃO}

\section{Aspectos de comunicação e organização}

Verificou-se nesse estudo que $45 \%$ dos empreendimentos não possuem acesso à internet ou informática, embora, $80 \%$ deles possuem sinal de telefonia móvel (figura 1). Os meios de comunicação na zona rural é uma ferramenta importante para o desenvolvimento de atividades econômicas (BERNARDES et al., 2015), que na carcinicultura facilita o contato entre os compradores de camarões e fornecedores de insumos.

Das propriedades pesquisadas, $65 \%$ delas possuem algum tipo de acompanhamento técnico, que em sua maioria é realizado por técnicos privados. Dotti et al. (2012) afirma que a falta de assistência técnica pode causa inúmeras perdas, principalmente quanto ao desempenho zootécnicos dos animais produzidos. Oitenta por cento dos empreendedores estavam associados à Associação dos Carcinicultores da Paraíba (ACPB), entidade que representa os produtores do Estado da Paraíba.

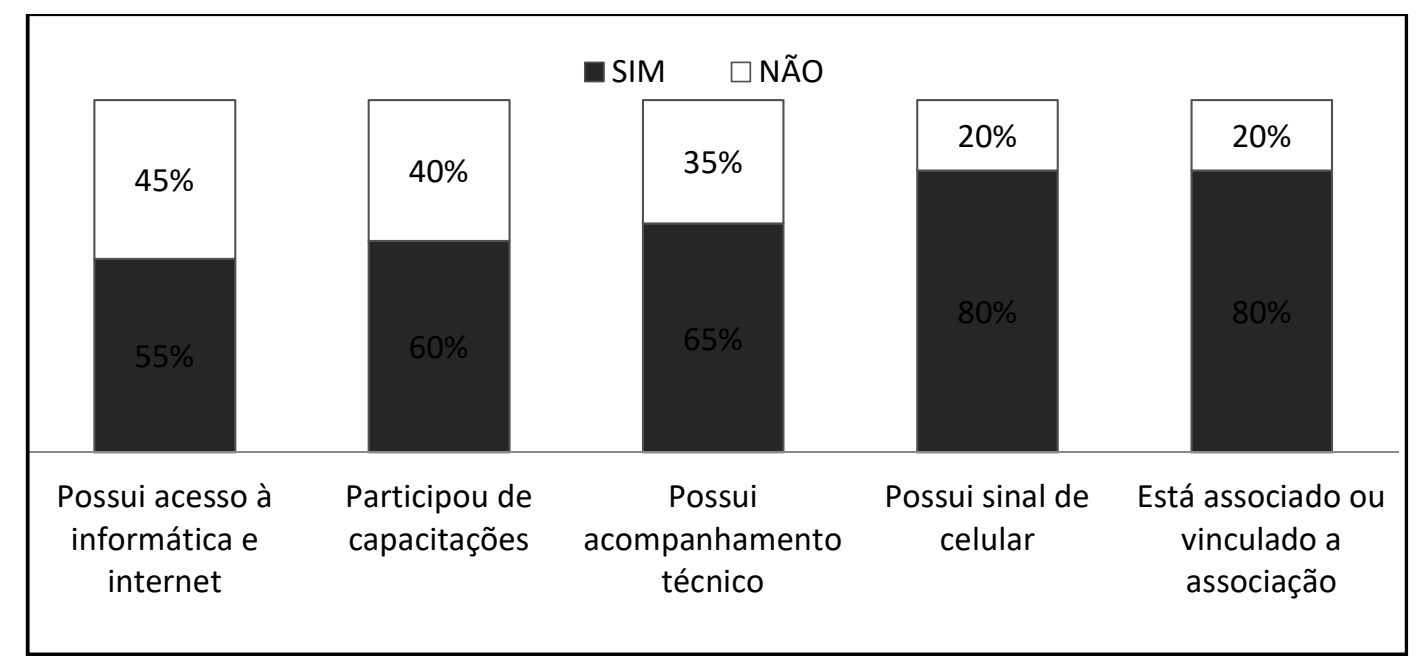

Figura 1: Resultados das entrevistas para os aspectos de comunicação e organização das propriedades de carcinicultura do Vale do Paraíba.

\section{Porte dos empreendimentos}

Em média, as propriedades visitadas tinham porte de 75ha de área total. As maiores possuem de 32 a 390ha, enquanto que as propriedades menores de 1 a 15ha. Em relação à área usada na produção de 
camarão (soma da lâmina de água) o tamanho médio verificado na região do Vale do Paraíba foi de 3.3ha, com variação de 0.5 a 11 ha entre as propriedades visitadas.

Os resultados mostram que 40\% dos empreendimentos possuem até 1 hectare de área produtiva, $35 \%$ possuem de 1.1 a 5 hectares e $25 \%$ dos empreendimentos são maiores que 5 hectares, conforme se nota na figura 2. Isso evidencia, segundo a Resolução CONAMA no413/2009, que a maioria das propriedades do Vale do Paraíba são classificadas em empreendimentos de pequeno porte, (BRASIL, 2009).

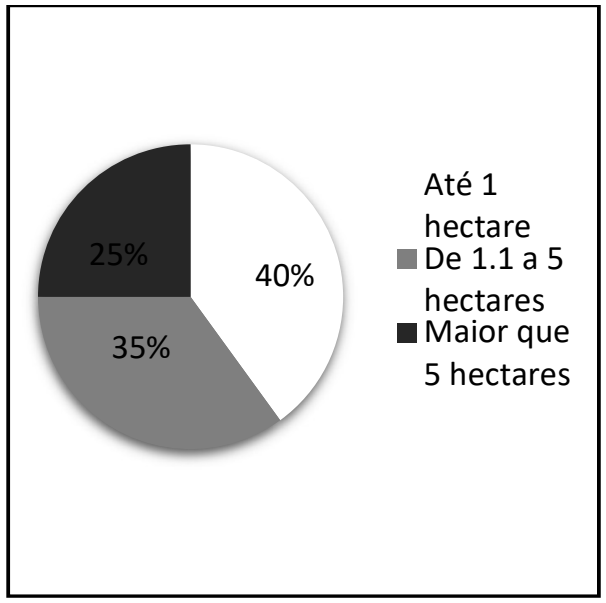

Figura 2: Porte dos empreendimentos de carcinicultura na região do Vale do Paraíba.

\section{Utilização de Energia Elétrica}

Todos os empreendimentos visitados possuem energia elétrica trifásica e $90 \%$ deles possuem desconto na tarifa no horário de $21 \mathrm{~h}$ às $06 \mathrm{~h}$, no qual há uma maior demanda de energia pelo uso noturno dos aeradores figura 3. Além disso, todos os empreendimentos fazem o uso de geradores de energia elétrica com potência que varia de 6.5 a 110KvA. A energia elétrica representa grande importância na carcinicultura já que permite o uso de aeradores, e consequentemente o aumento da produtividade e rentabilidade ao produtor (SILVA et al., 2009).

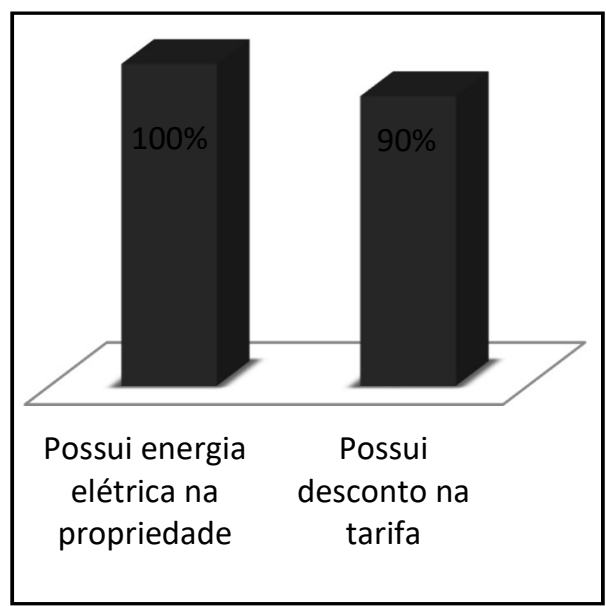

Figura 3: Utilização de energia elétrica nas propriedades.

\section{Mão de obra empregada}

Os empreendimentos de criação de camarão no Vale do Paraíba possuem características de micro e pequenos produtores. Dessa forma, $55 \%$ das carciniculturas atuam com mão de obra familiar, onde apenas 
duas pessoas conseguem realizar todo o trabalho que a produção demanda (figura 4). Geralmente o proprietário do empreendimento é o principal trabalhador. As propriedades de maior porte (acima de 1 hectare de área produtiva) possuem de 3 a 5 funcionários contratados para trabalharem no processo produtivo.

De acordo com Costa et al. (2004), a atividade gera 3.75 empregos diretos e indiretos para cada hectare de área com viveiros, sendo que $88 \%$ desses empregos são de baixa qualificação. Esse mesmo estudo revela que a carcinicultura gera mais empregos quando comparada a algumas culturas agrícolas presentes no Nordeste, como o coco, cana-de-açúcar, manga e uva, as quais geram, respectivamente, um total de empregos por hectare de $0.86,1.05,1.12$ e 2.14 .

O emprego proporcionado na carcinicultura beneficia diretamente os trabalhadores locais, sendo possível constatar que é uma atividade importante na geração de emprego e renda, principalmente porque fornece oportunidades a pessoas com baixo nível de instrução de se manterem empregadas (ARAÚJO et al, 2009).

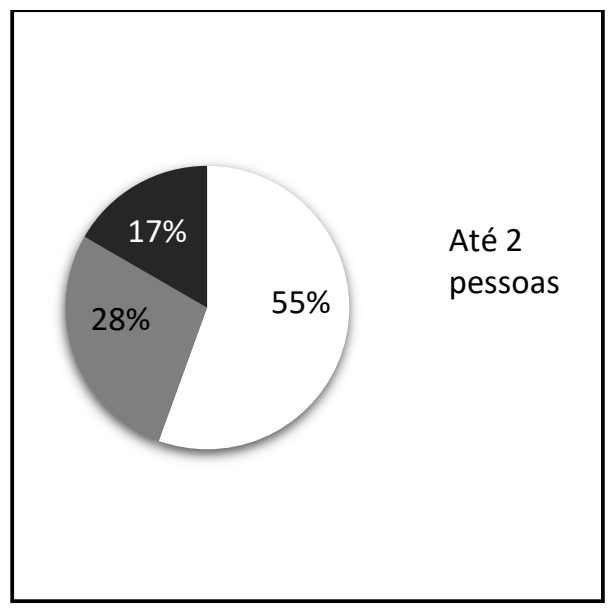

Figura 4: Número de pessoas que trabalham nos empreendimentos de carcinicultura na região do Vale do Paraíba.

\section{Características dos viveiros de produção}

Quanto à utilização de berçários (estrutura usada para a produção de juvenis), apenas 10\% dos empreendimentos utilizam, caracterizando uma produção em sistema bifásico, com melhor produtividade, porém, gera uma maior demanda por mão de obra e tecnologia. Em relação à quantidade de viveiros, 50\% das propriedades possuem até 5 viveiros, caracterizando pequenos produtores. Por outro lado, $20 \%$ das propriedades possuem de 6 a 10 viveiros ou mais que 15 viveiros (figura 5).

Os tamanhos dos viveiros das carciniculturas são em média de $2000 \mathrm{~m}^{2}$. No entanto, $37 \%$ dos empreendimentos possuem viveiros de 1001 a $2000 \mathrm{~m}^{2}, 21 \%$ de 3000 a $5000 \mathrm{~m}^{2}, 17 \%$ com até $1000 \mathrm{~m}^{2}, 13 \%$ acima de $5000 \mathrm{~m}^{2}$ e $12 \%$ dos empreendimentos possuem viveiros entre 2001 a $3000 \mathrm{~m}^{2}$, como se pode visualizar na figura 6. Observam-se, variações nos tamanhos dos viveiros, no entanto, é recomendável que os viveiros das carciniculturas tenham de 500 a $3000 \mathrm{~m}^{2}$, facilitando no planejamento e nas operações produtivas. 


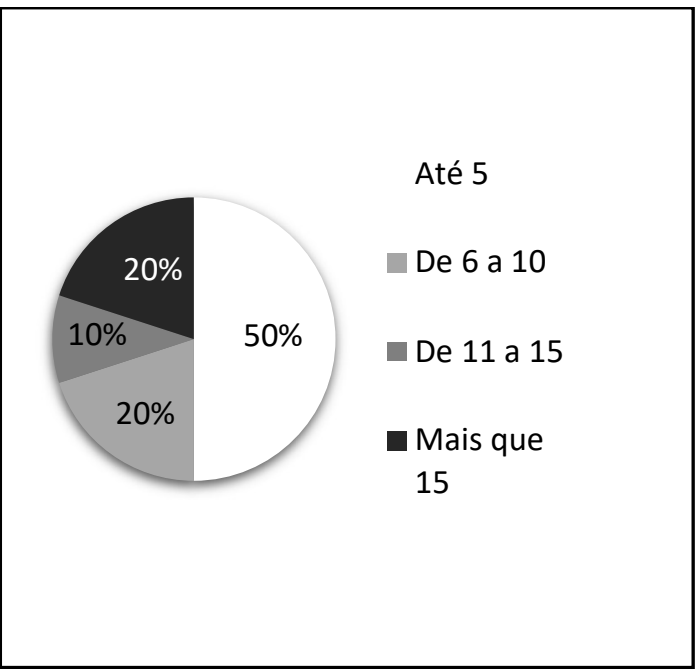

Figura 5: Quantidade de viveiros nos empreendimentos destinados a produção de camarões.

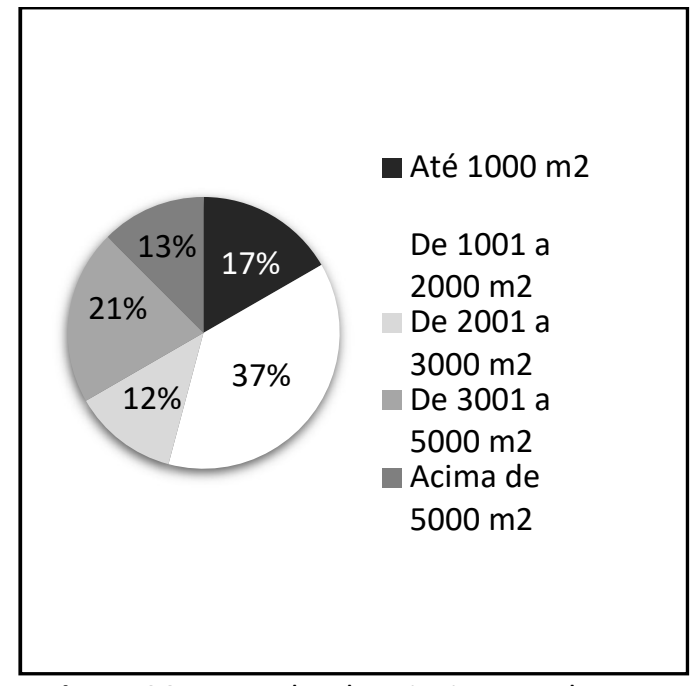

Figura 06: Tamanho dos viveiros usados nos empreendimentos do Vale do Paraíba.

\section{Densidade de estocagem}

Verificou-se que a densidade média adotada pelos produtores do Vale do Paraíba, no sistema de monocultivo é de 58 pós-larvas (PL 20), estocadas em cada $\mathrm{m}^{2}$ de viveiro. Entretanto, devido às diferentes características das propriedades como disponibilidade e qualidade de água, mão de obra e principalmente o uso de aeradores, observou-se que algumas propriedades utilizavam densidades entre 80 e 100 camarões por $\mathrm{m}^{2}$, porém, em outros empreendimentos, que tinham limitações desses fatores as densidades relatadas foram de 20 a 30 camarões por $\mathrm{m}^{2}$. Na figura 7, observa-se a densidade praticada em cada um dos empreendimentos entrevistados.

A densidade de estocagem de camarões é um dos principais fatores que determinam a sobrevivência, o crescimento e, consequentemente, a biomassa final produzida, devido a isso, as variações de densidade encontrada nesse estudo podem ser atribuídas a diferentes estratégias de produção e a disponibilidade de recursos hídricos, contudo, sempre com o intuito de obter uma maior produção sustentável para maximizar a produtividade (FERTILIZADOS et al., 2007).

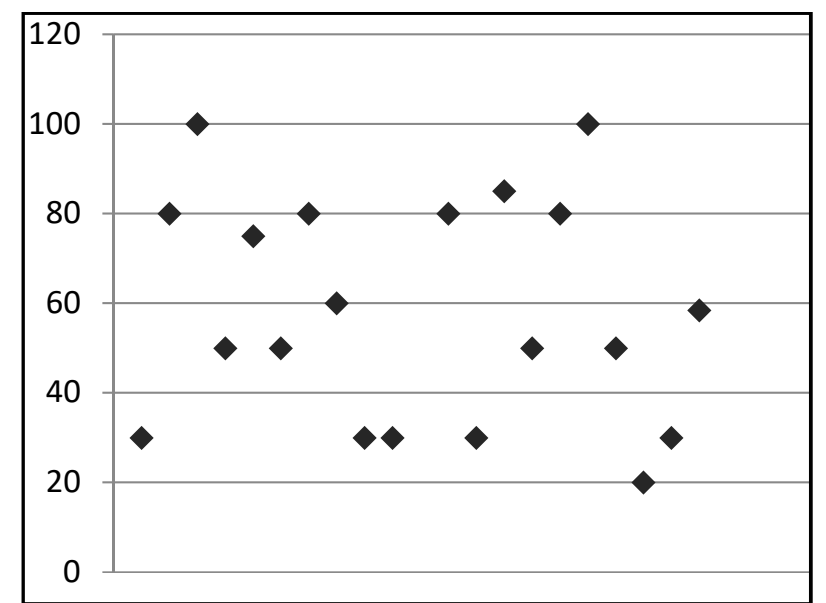

Figura 7: Variações da densidade de estocagem (número de pós-larvas por $\mathrm{m}^{2}$ ) entre as 20 propriedades entrevistadas. 


\section{Taxa de sobrevivência}

Os resultados desse estudo demonstram que a taxa de sobrevivência dos camarões durante o ciclo de produção variou de $65 \%$ a $100 \%$, valor considerado satisfatório entre os produtores. Na figura 8 é possível observar a taxa de sobrevivência em cada propriedade entrevistada. Esse indicador é influenciado pela qualidade das pós-larvas adquiridas, transporte, qualidade de água e manejo da produção. A sobrevivência também está relacionada com o tamanho do camarão na despesca, ou seja, os empreendimentos que produzem camarões maiores possuem a taxa de sobrevivência menor, pois os dias de cultivo são prolongados.

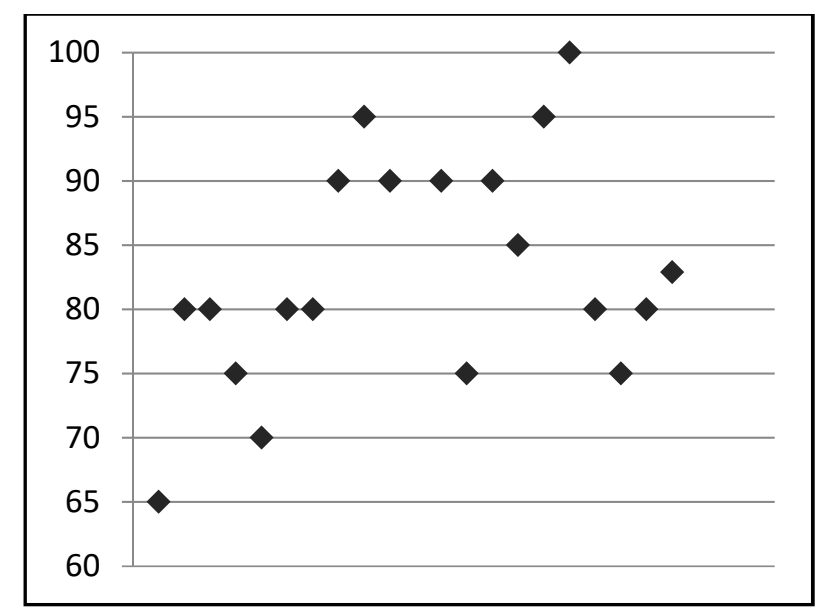

Figura 8: Taxa de sobrevivência média (\%) nas 20 propriedades entrevistadas.

O uso de aeradores é comum na carcinicultura, obtendo-se aumento de produtividade. Todos os empreendimentos desse estudo (100\%) utilizam aeradores, o que monstra bom acesso dos produtores a uma das principais tecnologias para aumento de produção. Por outro lado, observou-se que somente $5 \%$ dos empreendimentos fazem o uso de alimentadores automáticos, que ainda é uma tecnologia de alto custo.

\section{Ciclos de produção}

O camarão no Vale do Paraíba é produzido com peso entre 8 e 15 gramas, sendo que a maior demanda do mercado consumidor se concentra no camarão com 10g. Na tabela 1, é possível observar as faixas de peso, o tempo de cultivo e a quantidade de ciclos ao ano, em média, para a região do Vale do Paraíba. Nas propriedades visitadas, 50\% delas fazem o monitoramento ambiental, por meio de análises frequentes de qualidade da água. A outra parcela, que não realiza nenhum tipo de monitoramento ambiental, foram, principalmente, os pequenos produtores, com área em até 1 hectare.

Tabela 1: Faixa de peso, tempo de cultivo e quantidade de ciclos ao ano do camarão produzido no Vale do Paraíba.

\begin{tabular}{|c|c|c|}
\hline Faixa de peso & Tempo de cultivo (dias) & Ciclos ao ano \\
\hline $8-9 \mathrm{~g}$ & 72 & 3,6 \\
\hline $10 \mathrm{~g}$ & 82 & 3,8 \\
\hline $14-15 \mathrm{~g}$ & 92 & 3,3 \\
\hline
\end{tabular}

Os principais dados de qualidade da água monitorados pelos empreendimentos são: oxigênio dissolvido, $\mathrm{pH}$ e temperatura da água. Na figura 9 podem-se observar os parâmetros de qualidade de água 
monitorados pelos empreendimentos. O monitoramento ambiental da carcinicultura é fundamental para o bom desenvolvimento zootécnico da atividade, além de evitar possíveis impactos ao meio ambiente (CUNHA, 2004; RIBEIRO et al., 2014), causados por atividades aquícolas especialmente aos recursos hídricos (TORATI et al., 2014).

Diante disso, é necessário que as propriedades do Vale do Paraíba aumentem suas capacidades de monitoramento ambiental, investindo, sobretudo, em equipamentos e qualificação da mão de obra. As lagoas de decantação, usadas para o tratamento da água antes do descarte ao corpo hídrico, foram encontradas em $85 \%$ dos empreendimentos visitados. O tamanho médio das lagoas foi de $9.800 \mathrm{~m}^{2}$, e está relacionado ao tamanho e produtividade do empreendimento.

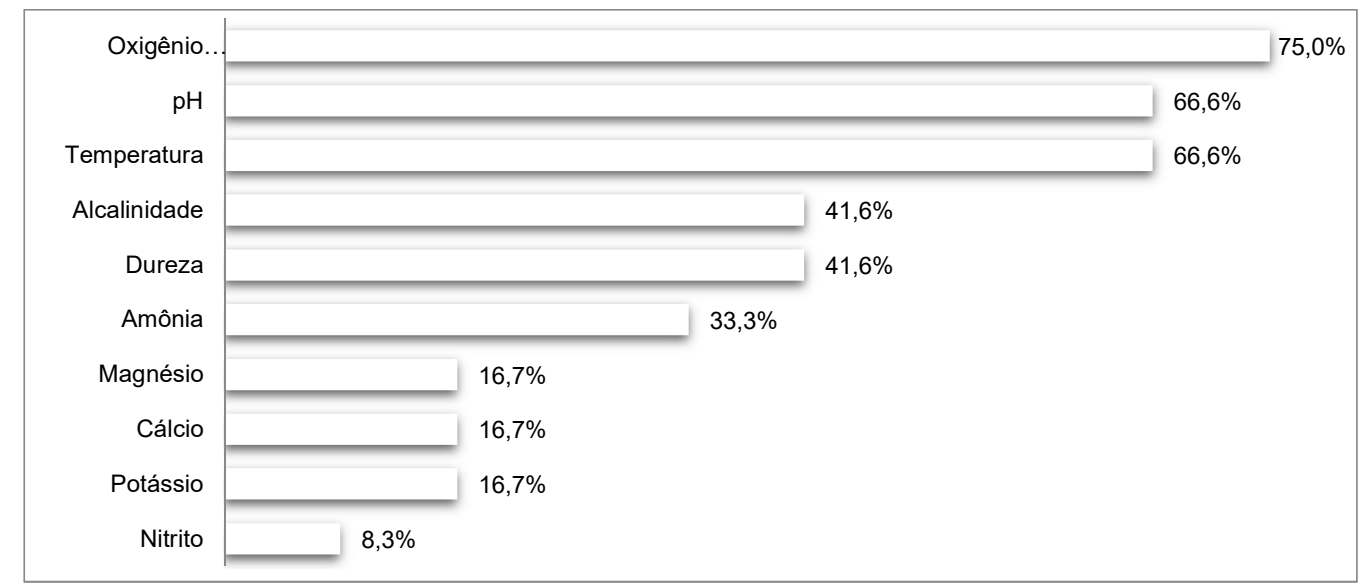

Figura 9: Principais parâmetros de qualidade da água monitorados pelos empreendimentos do Vale do Paraíba.

\section{Regularização Ambiental}

Quanto à regularização ambiental, observam-se, conforme predisposto na figura 10 , que $35 \%$ dos empreendimentos possuem o licenciamento ambiental, $25 \%$ deles a outorga de uso da água e somente $15 \%$ o cadastro ambiental rural (CAR). 0 registro de atividade pesqueira (RGP) é aderido por $80 \%$ das propriedades visitadas.

O aumento na regularização ambiental dos empreendimentos de carcinicultura do Vale do Paraíba se faz necessário para garantir a sustentabilidade do segmento, uma vez que, em alguns casos, a carcinicultura é associada a efeitos adversos nos ecossistemas adjacentes (RIBEIRO et al., 2014), entretanto, com poucas comprovações científicas.

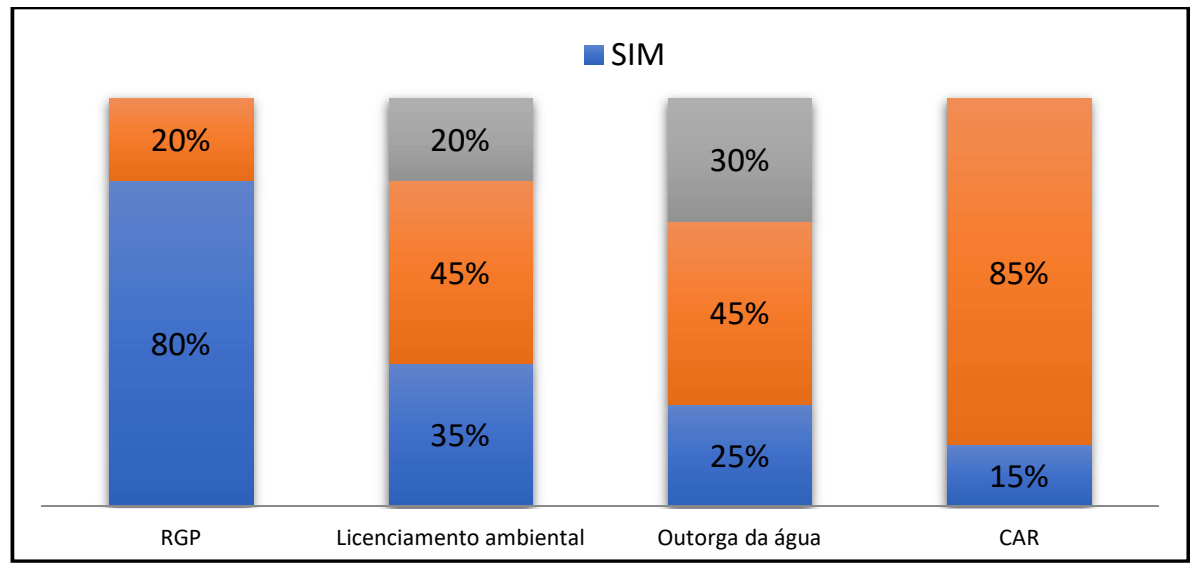

Figura 10: Regularização ambiental dos empreendimentos produtores de camarão do Vale do Paraíba. 


\section{CONCLUSÕES}

A carcinicultura na região do Vale do Paraíba, é uma atividade majoritariamente realizada por pequenos produtores com até 1 hectare de área produtiva. É necessário que os empreendimentos busquem a regularização quanto ao licenciamento ambiental, outorga de uso da água e o cadastro ambiental rural. Assim, evita-se a paralisação do negócio e diversos prejuízos. Além disso, é indispensável que os empreendimentos aumentem a capacidade de realizar um adequado monitoramento ambiental, sobretudo, quanto aos parâmetros de qualidade de água e efluentes gerados na produção, garantindo, assim, a sustentabilidade e continuidade da atividade produtiva. Os resultados desse estudo são de fundamental importância para subsidiar futuros estudos científicos e tecnológicos em prol da cadeia produtiva da carcinicultura.

\section{REFERÊNCIAS}

ABCC. Associação Brasileira de Criadores de Camarão. O Censo da carcinicultura nacional em 2011. Revista Associação Brasileira de Criadores de Camarão, v.15, n.1 p.24-28, 2013.

ARAÚJO, M. A. D.; OKINO, M. Y. F.. Qualidade dos empregos da carcinicultura na praia de Barreta/RN. Organizações Rurais \& Agroindustriais, v.11, p.1, 2009.

BERNARDES, J. C.; VIEIRA, S. C.; BONFIM, E. B.; SANT'ANA, R. C. G.. O uso das tecnologias de informação e comunicação na agricultura familiar: um caminho para a sustentabilidade. Periódico Eletrônico Fórum Ambiental da Alta Paulista, v.11, p.9, 2015.

DOI: http://doi.org/10.17271/1980082711920151175

BORGHETTI, N. R.; OSTRENSKY, A.; BORGHETTI, J.

R.. Aqüicultura: uma visão sobre a produção de organismos aquáticos no Brasil e no Mundo. Curitiba: EMBRAPA, 2003.

BRASIL. Resolução CONAMA n.413 de 26 de Junho de 2009. Dispõe sobre o licenciamento ambiental da aquicultura e da outras providências. Brasília: DOU, 2009.

CASTRO, A. A.; PAGANI, G. D.. Secagem e composição química da cabeça de camarão (Litopenaeus vannamei Boone) a diferentes temperaturas. Revista Brasileira de Produtos Agroindustriais, Campina Grande, v.6, n.2, p.123-129, 2004.

COSTA, E. F.; SAMPAIO, Y.. Geração de empregos diretos e indiretos na cadeia produtiva do camarão marinho cultivado. Revista Economia Aplicada, v.8, n.2, p.1-19, 2004.

CUNHA, P. E. V.. Caracterização dos meios de cultivo de viveiros de carcinicultura e da lagoa de disposição dos efluentes no Rio Grande do Norte: subsídios para proteção dos ecossistemas deste estudo. Tese (Doutorado em Hidráulica e Saneamento) - Universidade de São Paulo, São Paulo, 2004. DOI: http://doi.org/10.11606/D.18.2005.tde$\underline{22082007-185411}$

DIEGUES, A. C.. Para uma aqüicultura sustentável do Brasil. São Paulo: USP, 2006.
DOTTI, A.; VALEJO, P. A. P.; RUSSO, M. R.. Licenciamento ambiental na piscicultura com enfoque na pequena propriedade: uma ferramenta de gestão ambiental. Revista Ibero-Americana de Ciências Ambientais, v.3, n.1, p.6-16, 2012. DOI: http://doi.org/10.6008/ESS2179$\underline{6858.2012 .001 .0001}$

FAO. Food and Agriculture Organization. FishStatJ: Software for Fishery Statistical Time Series. Roma: FAO, 2016.

FAO. Food and Agriculture Organization. The State of World Fisheries and Aquaculture 2014. Roma: FAO, 2016.

FERTILIZADOS, E. M.; RENOVAÇÃO, C.; ÁGUA, D.. Grow out of the Litopenaeus vannamei in microcosms fertilized with wheat bran without water exchange. Archivos de zootecnia, v.56, n.214, p.181-190, 2007.

IBGE. Instituto Brasileiro de Geografia e Estatística. Produção da Pecuária Municipal 2014. Rio de Janeiro: IBGE, 2015.

JOVENTINO, F. K. P.; MAYORGA, M. I. O.. Diagnóstico socioambiental e tecnológico da carcinicultura no município de Fortim, Ceará, Brasil. Revista Eletrônica do Prodema, v.2, p.86-96, 2008

NATORI, M. M.; SUSSEL, F. R.; SANTOS, E. D.; PREVIERO, T. D. C.; VIEGAS, E. M. M.; GAMEIRO, A. H.. Desenvolvimento da carcinicultura marinha no Brasil e no mundo: avanços tecnológicos e desafios. Informações Econômicas, v.41, n.2, p.61-73, 2011.

RIBEIRO, L. F.; SOUZA, M. C.; BARROS, F.; HATJE, V.. Desafios da carcinicultura: aspectos legais, impactos ambientais e alternativas mitigadoras. Revista de Gestão Costeira Integrada, v.14, n.3, p.365-383, 2014. DOI: http://doi.org/10.5894/rgci453

ROCHA, I. P.. Carcinicultura brasileira: processos tecnológicos, impactos sócio-econômicos, sustentabilidade ambiental, entraves e oportunidades. Revista Associação Brasileira de Criadores de Camarão, v.13, n.1, p.13-23, 2011. 
ROCHA, I. P.. Impactos socioeconômicos e ambientais da carcinicultura brasileira: mitos e verdades. Revista Associação Brasileira de Criadores de Camarão, v.7, n.4, p.29-36, 2006.

ROCHA, I. P.; RODRIGUES, J. A.. Carcinicultura brasileira. Revista Associação Brasileira de Criadores de Camarão, v.5, p.30-45, 2003.

SILVA, J. L. M. D.; SAMPAIO, L. M. B.. Eficiência, gestão e meio ambiente na carcinicultura do Rio Grande do Norte. Revista de Economia e Sociologia Rural, v.47, n.4, p.883-902, 2009. DOI: http://doi.org/10.1590/S0103$\underline{20032009000400004}$
TAHIM, E. F.; ARAUJO JUNIOR, I. F.. A carcinicultura do nordeste brasileiro e sua inserção em cadeias globais de produção: foco nos APLs do Ceará. Revista de Economia e Sociologia Rural, v.52, n.3, p.567-586, 2014. DOI: http://doi.org/10.1590/S0103-20032014000300009

TORATI, L. S.; SILVA, A. P.; RODRIGUES, A. P. O.; LIMA, A. F.; MACIEL, P. O.; PEDROZA FILHO, M. X.; UMMUS, M. E.. Uso da água e caracterização ambiental de pisciculturas familiares do noroeste do Tocantins. Revista lberoAmericana de Ciências Ambientais, Aquidabã, v.5, n.2, p.96106, 2014. 